\title{
Fungal Carotenoids
}

\section{II.* The Structure of the Carotenoid Acid Neurosporaxanthin}

\author{
ARNE J. AASEN and SYNNØVE LIAAEN JENSEN
}

Institutt for Organisk Kjemi, Norges Tekniske Hфgskole, Trondheim, Norway

\begin{abstract}
The carotenoid acid neurosporaxanthin has been isolated from Neurospora crassa and $N$. sitophila. The elucidation of the structure as $\beta$-apo-4'-carotenoic acid $\left(\mathrm{C}_{35}\right)$ (V) was based on the following evidence:

Neurosporaxanthin and synthetic $\mathrm{V}$ have identical absorption spectra in visible and infrared light, the same partition ratios and cannot be separated chromatographically.

Neurosporaxanthin methylester and $\beta$-apo-4'-carotenoic $\left(C_{35}\right)$ methyl ester (VI) also agreed in the above physical properties and showed the same melting point.

Hydride reduction of neurosporaxanthin and VI gave the same mono-ol (VII) as judged by identity in visible light absorption spectra and chromatographic behaviour.

By comparison of absorption spectra in visible light, chromatographic properties and partition behaviour, it was established that the mono-ols (VII) gave the same aldehyde (IX) on allylic oxidation and the same acetate (VIII) on acetylation.

Some anomalous spectral features of neurosporaxanthin and derivatives are discussed.

Factors influencing the biosynthetic formation of neurosporaxanthin are briefly reviewed and a plausible pathway of bio. synthesis for neurosporaxanthin via $\gamma$-carotene $(\mathrm{XI})$ is considered.
\end{abstract}

A

mong the approximately one hundred and fifty naturally occurring carotenoids so far characterized, ${ }^{1,2}$ carotenoid acids are rather rare. To this group belong crocetin (I) from saffron, bixin (monomethylester of II) from the outer layer of the testa of Bixa orellana L., azafrin (III) isolated from the roots of Escobedia scabrifolia Ruiz et Pav., and torularhodin (IV) obtained from red yeast. 1,3

From fungi, Haxo ${ }^{4,5}$ has characterized another acidic carotenoid. This pigment was subsequently obtained in the crystalline state and designated neurosporaxanthin by Zalokar. ${ }^{6}$ Although neurosporaxanthin was isolated from Neurospora spp., ${ }^{4-6}$ Rau and Zehender ${ }^{7}$ have reported its possible

* Part I. Phytochemistry 4 (1965) 925. 
presence in Fusarium aquaeductum Lagh. (Fungi imperfecti), and Davies ${ }^{8}$ has suggested its occurrence in Rhizoflyctis rosea (de Bay and Woronin) Fisher (Phycomycetes).

The composition of the carotenoids produced by Neurospora spp. has been studied by many workers. ${ }^{4,5,9,10}$ During a re-investigation primarily undertaken to examine the natural distribution of the methoxylated carotenoid spirilloxanthin, ${ }^{11}$ we isolated neurosporaxanthin from Neurospora sitophila Shear and Dodge in spectroscopic quantities, sufficient for a tentative characterization as a $\beta$-apo- $4^{\prime}$-carotenoic acid $\left(\mathrm{C}_{35}\right)(\mathrm{V})$. Agreement in previously reported melting points and extinction coefficients for neurosporaxanthin ${ }^{6}$ and $\mathrm{V}$ synthesized by Isler et $a l .^{3}$ provided further support for this assumption.

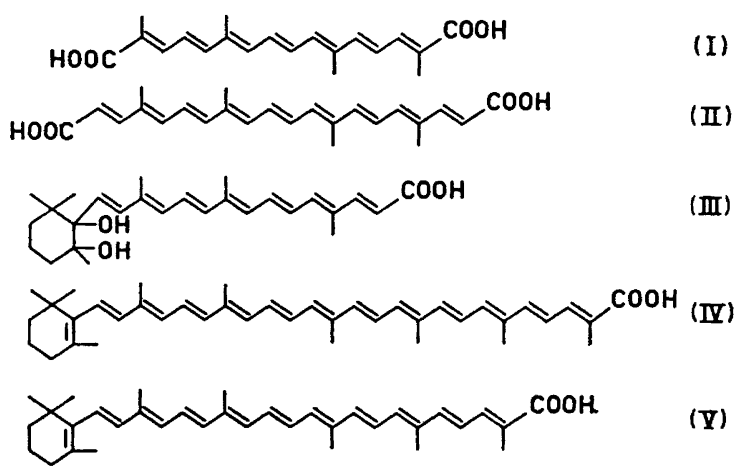

In the present work neurosporaxanthin has been isolated from $N$. sitophila and $N$. crassa Shear and Dodge and compared by physical and chemical methods with synthetic $V$.

\section{RESULTS AND DISCUSSION}

The degree of pigmentation of Neurospora spp. depends on the growth condition employed.4,9,10 Haxo ${ }^{4}$ reported that limited pigmentation of $N$. crassa occurred in submerged cultures, and Zalokar ${ }^{9}$ further confirmed the observation by others that light and oxygen were required for maximum pigmentation. The conidia produce larger quantities of carotenoids than the mycelium and differ in the relative concentration of the individual carotenoid components. ${ }^{9}$ Conidia are formed only in air, ${ }^{9}$ and formation is enhanced by growth in the medium devised by Horowitz. ${ }^{12,9}$ According to Zalokar ${ }^{6}$ the acidic carotenoid neurosporaxanthin is responsible for the pink colour of the mycelium.

Based on this information attempts were made to grow cultures of $N$. sitophila and $N$. crassa with maximum content of neurosporaxanthin. $N$. sitophila was cultivated essentially as recommended by Zalokar ${ }^{6}$ in submerged culture followed by exposure of the mycelia to light and oxygen. $N$. crassa was grown on a solidified agar medium in light and air according 
to Haxo ${ }^{4}$ with a final incubation under oxygen. Better pigmentation and relatively higher yields of neurosporaxanthin were obtained in the latter case, although our pigment yield did not approach that obtained by Zalokar. ${ }^{9}$

Haxo $^{5}$ states that the acidic carotenoid fraction of $N$. crassa includes at least three components. However, under the culture conditions used here, only a single acidic carotenoid with properties similar to those previously described for neurosporaxanthin ${ }^{6}$ could be isolated from $N$. crassa and N. sitophila.

Neurosporaxanthin showed acidic properties and, on methylation with diazomethane gave a product with an IR-spectrum typical of a methyl ester (see Fig. 2). Neurosporaxanthin is therefore a carotenoid acid. On hydride reduction it gave a compound with adsorptive and partition properties typical of a mono-ol with $\gamma$-carotene-like absorption spectrum.

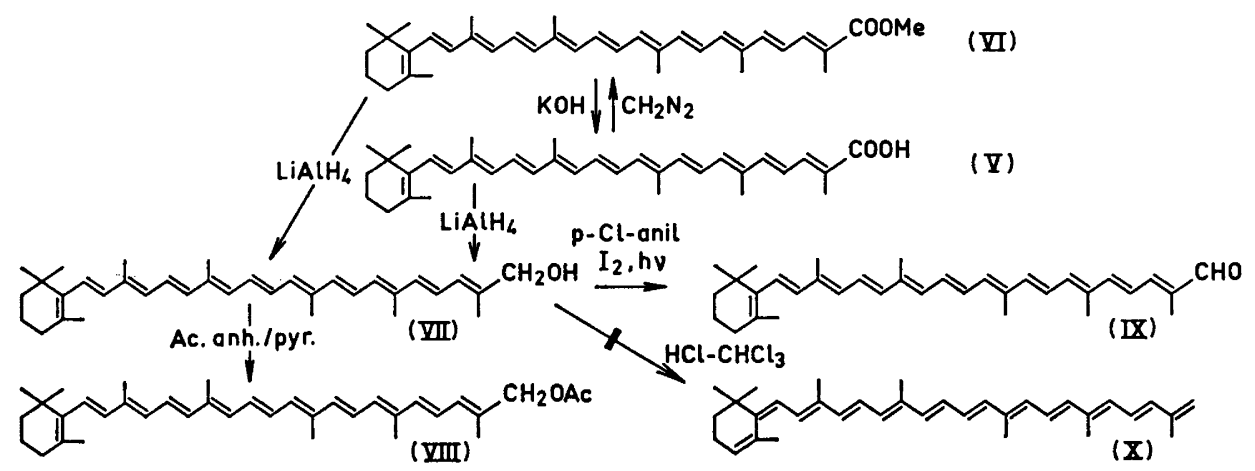

This mono-ol was readily acetylated and gave, on oxidation with $p$-chloranil under the catalytic influence of iodine and light, ${ }^{13}$ a conjugated aldehyde. These data indicated the structure $\mathrm{V}$ for neurosporaxanthin.

For comparison, synthetic $\beta$-apo-4'-carotenoic $\left(\mathrm{C}_{35}\right)$ methyl ester (VI) was saponified under strong conditions to $\beta$-apo-4'-carotenoic $\left(\mathrm{C}_{35}\right)$ acid (V).

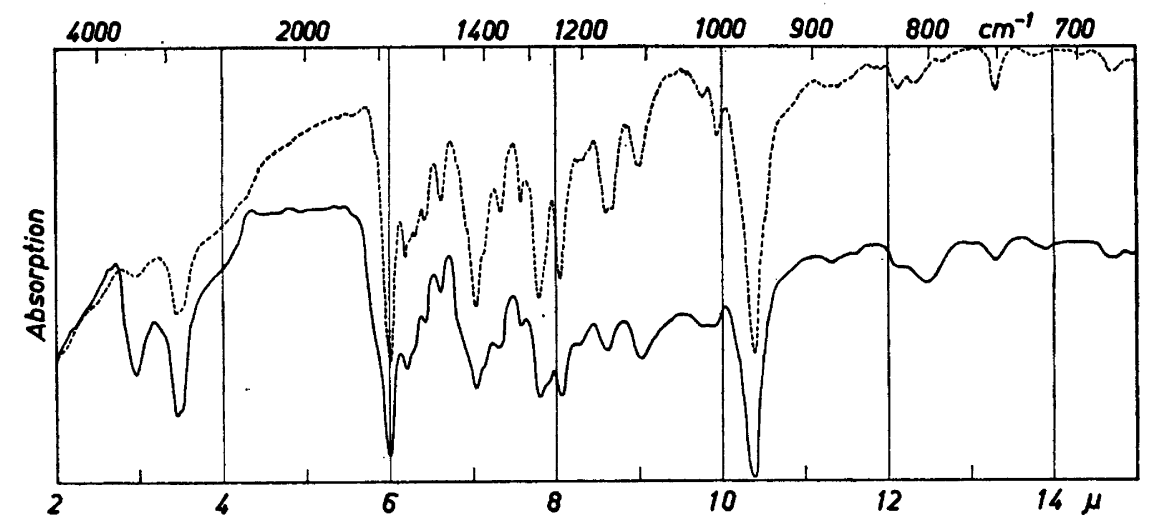

Fig. 1. IR-spectra in $\mathrm{KBr}$ of — neurosporaxanthin and- $--\beta$-apo-4'-carotenoic acid $\left(\mathrm{C}_{35}\right)$.

Acta Chem. Scand. 19 (1965) No. 8 
Good agreement was observed for the visible light absorption spectra and IRspectra (see Fig. 1) of the natural and synthetic acid. The two compounds exhibited the same partition ratio and could not be separated paper-chromatographically. However, judging from the extinction coefficient and melting point, the natural acid was of lower purity, although no melting point depression was observed in a mixed melting point determination.

Neurosporaxanthin methyl ester, however, agreed with synthetic VI in melting point as well as absorption spectra in visible light, IR-spectra (see Fig. 2), partition ratios and co-chromatography tests.

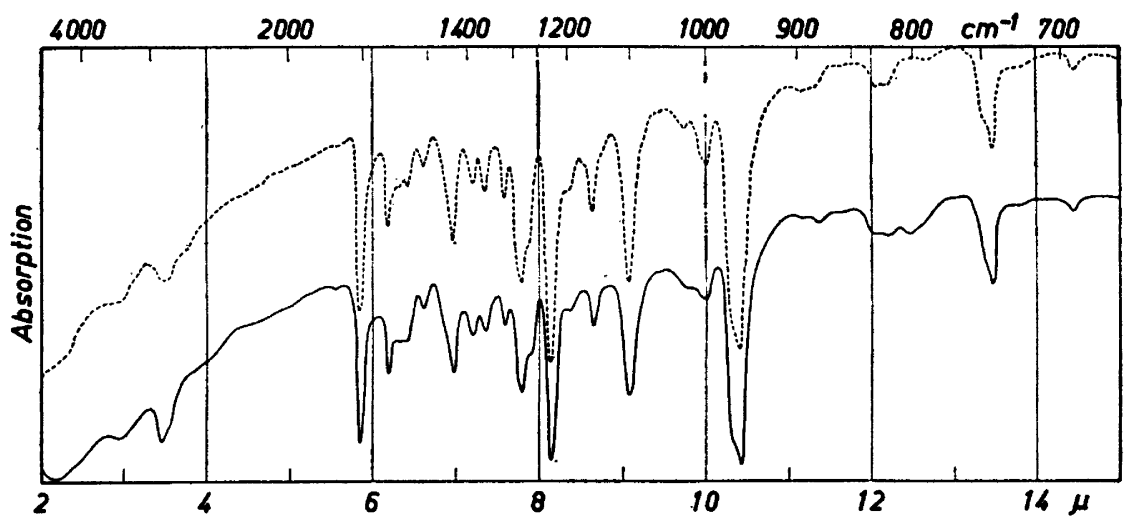

Fig. 2. IR-spectra in $\mathrm{KBr}$ of - neurosporaxanthin methyl ester and- $--\beta$-apo. $4^{\prime}$-carotenoic acid $\left(\mathrm{C}_{35}\right)$ methyl ester.

Furthermore, neurosporaxanthin and synthetic VI gave the same reduction product (VII) with $\mathrm{LiAlH}_{4}$. The mono-ols (VII) thus prepared agreed in visible light absorption properties as well as partition ratios and could not be separated paper-chromatographically.

Both mono-ols (VII) also gave the same acetate, as revealed by identical partition behaviour and chromatographic properties.

Finally the two mono-ols (VII) gave the same aldehyde (IX) on oxidation with $p$-chloranil. The aldehydes (IX) exhibited the same absorption spectra in visible light, showed the same partition behaviour and could not be separated paper-chromatographically.

Treatment of synthetic VII with acid chloroform according to the method of Karrer and Leumann ${ }^{14}$ did not result in the formation of $\mathrm{X}$, a somewhat unexpected result when compared with the ready formation of anhydrovitamin A on similar treatment of vitamin A. ${ }^{15}$

Based on the evidence discussed above, we consider the structure of neurosporaxanthin to be unequivocally established as $\beta$-apo-4'-carotenoic acid $\left(\mathrm{C}_{35}\right)(\mathrm{V})$. Its biosynthetic formation possibly occurs by oxidation of $\gamma$-carotene (XI) or torulene (XII); substances which are also synthesized by the Neurospora spp. in question. ${ }^{11}$ 


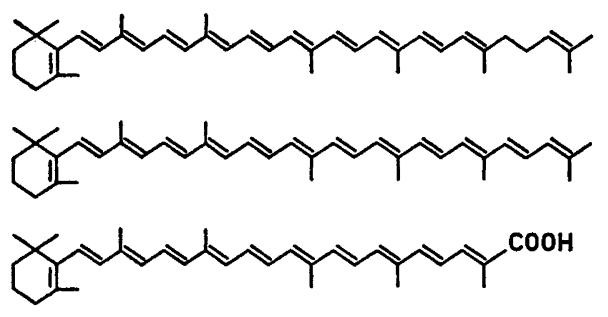

(XII)

(XII)

Finally some of the spectral features of the derivatives of neurosporaxanthin (V) deserve comment. Firstly the IR-spectra of carotenoid acids apparently do not disguise their carboxyl groups by blurred absorption in the 3500$3000 \mathrm{~cm}^{-1}$ region, as simple fatty acids generally do. Secondly the conjugated acid V does not display reduced fine-structure in the visible light absorption spectrum in methanol when compared with that observed in petroleum ether (see Fig. 3). This is a typical feature of conjugated carbonyl carotenoids. This is also true for the carotenoid acid azafrin (III). However, the ester (VI) and aldehyde (IX) do exhibit this spectral feature. It is also noteworthy that the maxima in methanol are at shorter wavelengths than those in petroleum ether for the conjugated carbonyl carotenoids V, VI, and IX (see Table 1).

\section{EXPERIMENTAL}

Materials and methods. Reagents and solvents used, except for acetone and pet.ether (boiling range $40-65^{\circ} \mathrm{C}$ ), were of analytical grade. Paper chromatography was carried out on Schleicher \& Schüll No. 287 circular paper (kieselguhr paper), ${ }^{16}$ Schleicher \& Schüll No. 597 paper (ordinary paper) or Schleicher \& Schüll no. 288 paper (aluminium oxide paper). For co-chromatography tests the 3-divided paper technique was used. ${ }^{17}$

Column chromatography of the acidic carotenoid was performed on Schleicher \& Schüll No. 124 cellulose powder or magnesium silicate (Johns Mansville \& Co.). ${ }^{18}$ Neutral carotenoids were chromatographed on Woelm neutral alumina, activity grade $2 .{ }^{19}$

Fig. 3. Absorption spectra in visible light of neurosporaxanthin $(V)$ in $\longrightarrow$ pet.ether and-.-methanol.

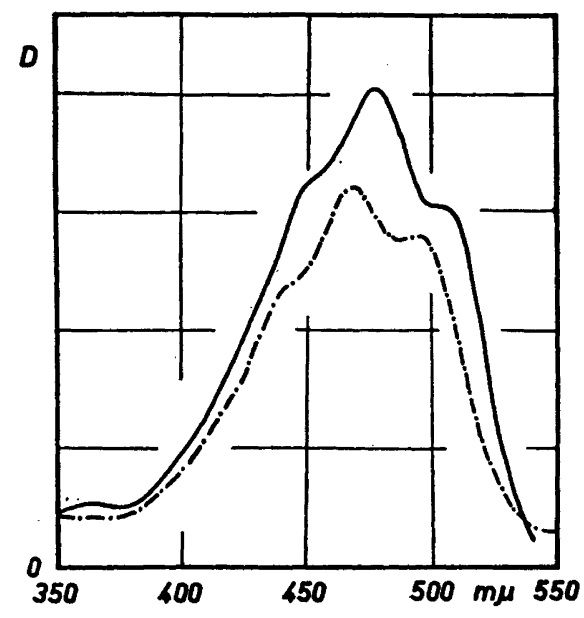

Acta Chem. Scand. 19 (1965) No. 8 
Table 1. Absorption maxima $(\mathrm{m} \mu)$ in visible light of neurosporaxanthin and some derivatives.

\begin{tabular}{|c|c|c|c|}
\hline Carotenoid & Pet.ether & Methanol & Acetone \\
\hline $\begin{array}{l}\text { Neurosporaxanthin = } \\
\beta \text {-Apo-4'-carotenoic acid }\left(C_{35}\right)(\mathrm{V}) \\
\text { Neurosporaxanthin methylester }= \\
\beta \text {-Apo-4'-carotenoic acid }\left(\mathrm{C}_{35}\right) \\
\text { methyl ester (VI) } \\
\text { Neurosporaxanthin aldehyde }= \\
\beta \text {-Apo-4'-carotenal }\left(\mathrm{C}_{35}\right)(\mathrm{IX})\end{array}$ & $\begin{array}{ll}477 & 505 \\
& \\
474 & 505 \\
482 & 512 \\
\end{array}$ & $\begin{array}{ll}471 & 505 \\
472 & (495) \\
480 & \end{array}$ & 472 \\
\hline
\end{tabular}

Absorption spectra in visible light were recorded on a Beckman DB Spectrophotometer. Infrared spectra were recorded on a Perkin Elmer Model 21 Instrument in KBrdiscs, prepared as described elsewhere. ${ }^{20}$

Melting points were measured in evacuated capillary tubes on a Berl block and are uncorrected.

Partition ratios were measured according to the method of Petracek and Zechmeister, ${ }^{21}$ as modified by Liaaen Jensen. ${ }^{22}$ Iodine catalyzed stereoisomerization was carried out as described earlier. ${ }^{22}$ Acetylations were conducted in dry pyridine and acetic anhydride overnight at room temperature. ${ }^{22}$

\section{Neurospora sitophila}

Culture. $N$. sitophila Shear and Dodge was obtained from Centraalbureau vor Schim. melcultures, Baarn, Netherlands.

Medium and cultural conditions. The medium devised by Horowitz ${ }^{12}$ with the addition of $1 \mathrm{~g}$ Bacto-Difco yeast extract per liter was used; $\mathrm{pH}$ ca. 6.5. Cultures $(4 \times 2500 \mathrm{ml})$ were grown in aerated flasks at $35^{\circ} \mathrm{C}$, using a $6 \% 2$ day old inoculum. After 6 days the mycelial mat was filtered on a Gooch crucible without suction and illuminated in an atmosphere of oxygen. The wet mycelial suspension was placed on several Petri dishes (depth of mycelial layer ca. $5 \mathrm{~mm}$ ), placed in a transparent plastic tent filled with oxygen and illuminated with two electric bulbs of $150 \mathrm{~W}$ at a distance of $40 \mathrm{~cm}$. After 1 day the mycelial mat turned slightly orange.

Pigment extraction and yields. The mycelial suspension was filtered on a gooch crucible and the residue repeatedly extracted with methanol in a Warring blendor. The pigments were transferred to petroleum ether in a separating funnel after addition of $0.1 \mathrm{~N}$ aqueous $\mathrm{HCl}$. The carotenoids were subsequently partitioned between pet.ether and alkaline methanol ( $1 \% \mathrm{KOH}$ in $90 \%$ methanol-water) and the hypophasic acidic carotenoids were transferred to pet.ether after acidification with dilute acetic acid.

After drying at $100^{\circ} \mathrm{C}$ for 1 day, the mycelial residue weighed $29.5 \mathrm{~g}$ and the total carotenoid content (determined spectrophotometrically using $E_{1}^{1} \mathrm{~cm} \lambda_{\max }=2500$ ) was $1.14 \mathrm{mg}$; only $0.0033 \%$ of the dry residue. The neutral carotenoids comprised $71 \%$ and the acid carotenoid $29 \%$ of the total carotenoid.

Saponification. On concentration the acid fraction gave an oily residue which prevented the adsorption of the acid carotenoid on a cellulose column. Saponification was carried out in $10 \% \mathrm{KOH}$-methanol for $2 \mathrm{~h}$ at room temperature and the reaction mixture was worked up in the usual manner by transfer of the pigments to ether; carotenoid recovery was $0.24 \mathrm{mg}(73 \%)$.

Chromatographic separation. The alkali-treated acid carotenoid fraction was again submitted to column chromatography on cellulose powder. 


\section{Neurosporaxanthin (V)}

Neurosporaxanthin was eluted from the above column with pet.ether and it exhibited abs. $\max$. at $477 \mathrm{~m} \mu$ in that solvent; $R_{F}=0$ on aluminium oxide paper; $30 \%$ acetone. pet.ether.

\section{Hydride reduced neurosporaxanthin (VII)}

Neurosporaxanthin $(0.10 \mathrm{mg}$; spectrophotometrically determined amount) was reduced with $\mathrm{LiAlH}_{4}$ in dry ether in the usual manner; ${ }^{24} 67 \%$ pigment recovery. The mono-ol obtained required 15-20\% acetone-pet.ether for elution from deactivated alumina and exhibited a partition ratio of $62: 38$ in pet.ether $/ 95 \%$ methanol. The paperchromatographically purified trans isomer had abs. max. at 433, 459, and $488 \mathrm{~m} \mu$ in pet.ether and (440), 462.5, and $492.5 \mathrm{~m} \mu$ in acetone, and was inseparable from trans synthetic VII on kieselguhr paper; $R_{F}=0.44$ in $5 \%$ acetone-pet.ether. Upon iodine catalysis in light, neo A (abs. max. 430, 453, and $481.5 \mathrm{~m} \mu$ in pet.ether, $c a .15 \%$ of total, $R_{F}=0.53$ in the above system), and neo B (abs. max. (429), 450.5, and 479.5 $\mathrm{m} \mu$ in pet.ether, $c a .15 \%$ of total, $R_{F}=0.60$ ) were produced. Complete agreement was also observed on co-chromatography of the stereoisomeric sets obtained on iodine-catalyzed isomerization of natural and synthetic VII.

\section{Hydride reduced neurosporaxanthin acetate (VIII)}

VII $(0.3 \mathrm{mg}$ ) in $4 \mathrm{ml}$ dry pyridine was treated with $1 \mathrm{ml}$ acetic anhydride in the usual manner; pigment recovery $78 \%$. The reaction mixture contained exclusively VIII; abs. max. 433,459 , and $488 \mathrm{~m} \mu$ in pet.ether. The acetate was completely epiphasic when partitioned between pet.ether $/ 95 \%$ methanol, and could not be separated from synthetic VIII; $R_{F}=0.53$ on kieselguhr paper, $1 \%$ acetone-pet.ether.

\section{$N$ eurospora crassa}

Culture. Neurospora crassa Shear and Dodge was obtained from Centraalbureau vor Schimmelcultures, Baarn, Netherlands.

Medium and cultural conditions. The microorganism was cultivated successfully in the medium employed for $N$. sitophila with the addition of $1 \%$ Bacto-Difco agar. The Fernbach flasks $(26 \times c a .200 \mathrm{ml})$ were inoculated from agar slants. After incubation for 15 days at $30^{\circ} \mathrm{C}$ under air, the cultures were incubated for one day in an atmosphere of oxygen (plastic tent). They were illuminated $(4 \times 150 \mathrm{~W}$ electric bulbs at $40 \mathrm{~cm}$ distance) throughout the cultivation.

Pigment extraction and yields. The mycelial mat was easily peeled from the agar substrate (provided not more than $1 \%$ agar was used) and kept in acetone for 2 days prior to repeated extraction with acetone in a Warring blendor. The acetone extract was concentrated and the carotenoids transferred to pet.ether in a separating funnel on dilution with $5 \%$ aqueous $\mathrm{NaCl}$-solution. Further procedure was as described for $N$. sitophila above. The dried mycelial residue amounted to $27 \mathrm{~g}$; spectrophotometrically determined carotenoid content $\mathbf{9 . 0} \mathrm{mg}$ or $0.033 \%$ of the dry residue. The neutral carotenoids comprised $58 \%$ and the acidic carotenoid $42 \%$ of the total.

\section{Neurosporaxanthin (V)}

Chromatographic purification. Owing to oily contaminants the acid carotenoid fraction was not adsorbed on a cellulose column. Chromatography was then carried out on magnesium silicate. $C$ is neurosporaxanthin required pure methanol and the trans isomer $1 \%$ acetic acid in methanol for elution. Other pigmented zones were not observed. Attempts to crystallize the chromatographically purified carotenoid from

Acta Chem. Scand. 19 (1965) No. 8 
various solvents were unsuccessful and saponification was employed as the next step in the purification procedure.

Saponification was carried out for $1 \mathrm{~h}$ at room temperature in $5 \% \mathrm{KOH}$-methanol. The reaction mixture was worked up in the usual manner and the pigment was re-chromatographed on magnesium silicate. The main fraction now required $50 \%$ methanol-ether for elution.

Crystallization of the remaining $1.4 \mathrm{mg}$ (spectrophotometrically determined amount) was again attempted from ether-pet.ether; total yield ca. $0.4 \mathrm{mg}$. The first batch had m.p. $154^{\circ} \mathrm{C}$ (synthetic $\mathrm{V}$ had m.p. $193^{\circ} \mathrm{C}$ and $\operatorname{mixed} \mathrm{m} . \mathrm{p} .165^{\circ} \mathrm{C}$ ) and the second batch m.p. $165-175^{\circ} \mathrm{C}$.

$\boldsymbol{R}_{F}$-value and co-chromatography tests. Crystalline, trans neurosporaxanthin exhibited $R_{F}=0.25$ on kieselguhr paper in $30 \%$ acetone-benzene and could not be chromatographically separated from synthetic $\mathrm{V}$ in this system.

Absorption spectrum in visible light. Abs. maxima were located at $477.5\left(E_{1 \%}^{1} \mathrm{~cm}=\right.$ 1715) and (504) $\mathrm{m} \mu$ in pet.ether (see Fig. 3) and at 471.5 and (496) $\mathrm{m} \mu$ in acetone.

$I R$-spectrum of $0.2 \mathrm{mg}$ in $0.6 \mathrm{~g} \mathrm{KBr}$ is shown in Fig. 1 .

Partition ratio in pet.ether $/ 85 \%$ methanol was found to be $98: 2$.

\section{Neurosporaxanthin methylester (VI)}

Preparation. Neurosporaxanthin (0.84 $\mathrm{mg}$, spectrophotometrically determined amount) was treated with an ether solution of diazomethane, prepared according to the procedure of Arndt. ${ }^{23}$ After $18 \mathrm{~h}$ at $-20^{\circ} \mathrm{C}$ the volatile matter was removed by concentration. The carotenoids were dissolved in ether leaving some white substance behind; carotenoid recovery $80 \%$. The carotenoid fraction was purified by chromatography on deactivated alumina. The methyl ester required $20 \%$ ether-pet.ether for elution.

Crystallization. The purest fraction $(0.38 \mathrm{mg})$ yielded, on crystallization from etherpet.ether, ca. $0.22 \mathrm{mg} \mathrm{VI}$; m.p. $142.5^{\circ} \mathrm{C}$. The melting point $\left(143^{\circ} \mathrm{C}\right)$ for synthetic VI was recorded at the same time.

$R_{F}$-value and co-chromatography tests. Neurosporaxanthin methyl ester had $R_{F}=0.63$ on kieselguhr paper in $2 \%$ acetone-pet.ether and could not be separated from synthetic VI in that system.

Absorption spectra in visible light of the trans isomer are given in Fig. 4. In pet.ether the abs. max. were located at $(360), 473.5\left(E_{1}^{1} \%=2800\right)$, and $504 \mathrm{~m} \mu$ and in methanol at $473 \mathrm{~m} \mu$.

$I R$-spectrum of $0.2 \mathrm{mg}$ in $0.6 \mathrm{~g} \mathrm{KBr}$ is presented in Fig. 2.

Partion ratio in pet.ether $/ 95 \%$ methanol was determined as 98:2.

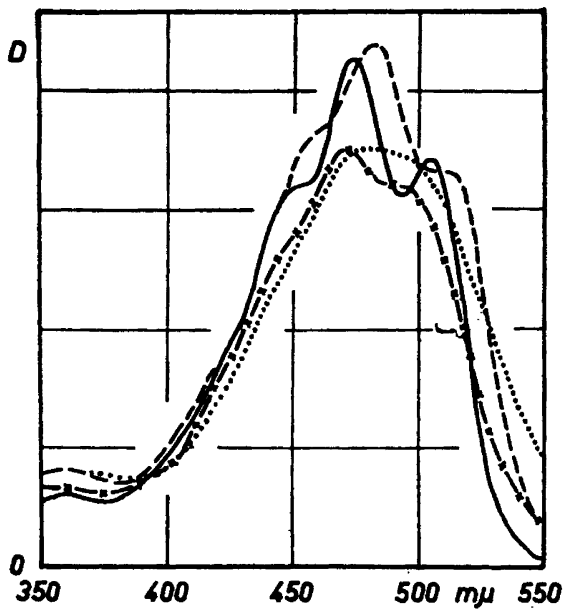

Fig. 4. Absorption spectra in visible light of neurosporaxanthin methylester (VI) in pet.ether, $\times \longrightarrow \times$ neurospora. xanthin methyl ester in methanol, - - neurosporaxanthin aldehyde (IX) in pet.ether and ...... neurosporaxanthin aldehyde in methanol. 


\section{H ydridereduced neurosporaxanthin (VII)}

Preparation. VII was prepared by $\mathrm{LiAlH}_{4}$-reduction of $0.19 \mathrm{mg}$ neurosporaxanthin methyl ester (VI) in dry ether; pigment recovery $56 \%$.

$\boldsymbol{R}_{F}$-value and co-chromatography tests. The prepared mono-ol had $R_{F}=0.46$ on kieselguhr paper ( $5 \%$ acetone-pet.ether) and could not be separated from totally synthetic VII, nor from partially synthetic VII from $N$. sitophila.

Absorption spectrum in visible light. In pet.ether, maxima were located at 433, 459, and $488.5 \mathrm{~m} \mu, \% \mathrm{III} / \mathrm{II}{ }^{23}=59$ and in acetone at $(440), 462$, and $491 \mathrm{~m} \mu$.

Partition ratio. In pet.ether $/ 95 \%$ methanol 62:38.

Hydride reduced neurosporaxanthin acetate (VIII)

Preparation. To $c a .0 .08 \mathrm{mg}$ VII in $6 \mathrm{ml}$ dry pyridine was added $1 \mathrm{ml}$ acetic anhydride. After $17 \mathrm{~h}$ a pigment recovery of $0.07 \mathrm{mg}$ VIII, abs. max. (440), 462, and $491 \mathrm{~m} \mu$ in pet.ether, was obtained.

$R_{F}$-value and co-chromatography tests. The acetate had $R_{F}=0.51$ on kieselguhr paper, $1 \%$ acetone-pet.ether, and could not be separated from synthetic VIII.

Saponification. The acetate $(0.07 \mathrm{mg})$ was saponified for $2 \mathrm{~h}$ in $8 \% \mathrm{KOH}$-methanol. VII $(0.04 \mathrm{mg})$ was obtained.

\section{Neurosporaxanthin aldehyde (IX)}

Preparation. VII $(0.04 \mathrm{mg})$ was dissolved in $4 \mathrm{ml}$ benzene, and $0.126 \mathrm{mg} p$-chloranil and $0.002 \mathrm{mg} \mathrm{I}_{2}$ was added. After $25 \mathrm{~h}$ in artificial Na-light ${ }^{13} \mathrm{a}$ conversion of approximately $90 \%$ to IX was observed.

$R_{F^{-}-v a l u e}$ and co-chromatography tests. The aldehyde had $R_{F}=0.65$ on kieselguhr paper in $5 \%$ acetone-pet.ether and could not be separated from totally synthetic IX.

Absorption spectrum in pet.ether had abs. max. at $481.5 \mathrm{~m} \mu$ and in methanol at $479 \mathrm{~m} \mu$; see Fig. 4.

Hydride reduction. $\mathrm{LiAlH}_{4}$-reduction of $\mathrm{IX}$ in dry ether on a micro scale resulted in the formation of VII as judged from the visible light absorption spectrum and chromatographic behaviour of the reduction product.

$$
\begin{gathered}
\text { Totally synthetic carotenoids } \\
\text { B-A po-4'-carotenoic acid }\left(\mathrm{C}_{35}\right) \text { methylester }
\end{gathered}
$$

This compound was kindly provided by Hoffman-La Roche, Basel. The totally synthetic specimen was characterized by the following properties:

Melting point: $143^{\circ} \mathrm{C}$.

Absorption spectrum in visible light. Abs. max. in pet.ether were located at (360), 476 $\left(E_{1}^{1} \%=3000\right)$ and $506 \mathrm{~m} \mu$, and in methanol at $470.5 \mathrm{~m} \mu$.

$I R$-spectrum of $0.27 \mathrm{mg}$ in $0.2 \mathrm{~g} \mathrm{KBr}$ is presented in Fig. 2.

Partition test: In pet.ether $/ 95 \%$ methanol 94:6.

$R_{F}$-value: After stereoisomerization in light the following $R_{F}$-values were found on kieselguhr paper (2\% acetone-pet.ether): trans $(0.72)$, neo A $(0.76)$ and neo $B(0.86)$.

$$
\beta-A \text { p o-4'-c arotenoic a cid }\left(C_{35}\right) \text { (V). }
$$

Preparation. Synthetic VI (4.69 $\mathrm{mg})$ was dissolved in a small volume of ether and treated with excess of $15 \% \mathrm{KOH}$-methanol at room temperature. After $17 \mathrm{~h}$ the saponification process was complete, as determined by periodic paper-chromatographic analysis of aliquots of the reaction mixture; pigment recovery $98 \%$.

Acta Chem. Scand. 19 (1965) No. 8 
Crystallization was carried out from acetone-pet.ether; yield $2.85 \mathrm{mg}$, m.p. $193^{\circ} \mathrm{C}$.

Absorption spectrum in visible light. Trans $\mathrm{V}$ had abs. max. at $473\left(E_{1 \mathrm{~cm}}^{1 \%}=2460\right)$

and (496) $\mathrm{m} \mu$ in acetone, 470 and $495 \mathrm{~m} \mu$ in methanol and 477 and $505 \mathrm{~m} \mu$ in pet.ether. After stereoisomerization in diffuse daylight for $10 \mathrm{~h}$ abs. max. in pet.ether shifted to $471 \mathrm{~m} \mu$.

$I R$-spectrum of $0.25 \mathrm{mg}$ in $0.2 \mathrm{~g} \mathrm{KBr}$ is presented in Fig. 1.

Partition test: In pet.ether $/ 85 \%$ methanol 98:2.

$R_{F}$-value. Trans $\mathrm{V}$ had $R_{F}=0.26$ on kieselguhr paper (30\% acetone-pet.ether) and $R_{F}=0.33$ on ordinary paper (5\% acetone-pet.ether).

\section{$\beta$-A p o-4'-c a r o t e n o l $\left(\mathrm{C}_{35}\right)$ (VII)}

Preparation. Synthetic VI (4.82 $\mathrm{mg})$ in dry ether was reduced with $\mathrm{LiAlH}_{4}$ in the usual manner; pigment recovery $93 \%$. The reaction mixture was chromatographed on a column of deactivated alumina. VII required $15-20 \%$ acetone-pet.ether for elution.

Absorption spectrum in visible light. Paper-chromatographically purified trans VII had abs. $\max .434,459.5$, and $489 \mathrm{~m} \mu$, \% III/II ${ }^{22}=59$ in pet.ether, and abs. $\max .440$, 463 , and $493 \mathrm{~m} \mu$ in acetone.

Partition ratio. In pet.ether $/ 95 \%$ methanol $61: 39$.

$R_{F}$-value and stereoisomerization studies. The iodine catalyzed equilibrium mixture had the following composition. $R_{F}$-values were measured on kieselguhr paper $(5 \%$ acetone-pet.ether) and abs. max. are given in acetone: Trans $\left(R_{F}=0.50\right)$, abs. max. (440), 463, and $493 \mathrm{~m} \mu, c a .60 \%$ of total; neo $\mathrm{A}\left(R_{F}=0.56\right)$, abs. $\max .454 .5$ and $481 \mathrm{~m} \mu$, ca. $20 \%$ of total; neo B $\left(R_{F}=0.63\right)$, abs. $\max .452$ and $480 \mathrm{~m} \mu, c a .20 \%$ of total.

Treatment with acid chloroform. Repeated experiment following the procedure of Entschel and Karrer ${ }^{24}$ gave no product with prolonged chromophore like $\mathrm{X}$.

Autoxidation to $I X$. When a solution of VII was stored in inert atmosphere autoxidation to IX occurred. Similarly iodine catalysis in light in the presence of oxygen resulted in partial conversion to IX.

\section{B-A p o-4'-carotenol $\left(\mathrm{C}_{35}\right)$ a cetat e (VIII)}

Preparation. Synthetic VII $(0.07 \mathrm{mg})$ in $4 \mathrm{ml}$ pyridine was treated with $1 \mathrm{ml}$ acetic anhydride for $15 \mathrm{~h}$; pigment recovery $94 \%$.

Absorption spectrum in visible light was similar to that of VII.

Partition ratio. In pet.ether $/ 95 \%$ methanol 96:4.

$R_{F}$-value. Trans VIII had $R_{F}=0.53$ on kieselguhr paper ( $1 \%$ acetone-pet.ether).

$$
\beta \text {-A p o-4'-c a rote n a } 1\left(\mathrm{C}_{35}\right) \text { (IX) }
$$

Preparation. IX was prepared by undesired autoxidation of VII (see above), or by oxidation of VII $(0.03 \mathrm{mg})$ in $3 \mathrm{ml}$ benzene with $0.075 \mathrm{mg} p$-chloranil and $0.0013 \mathrm{mg} \mathrm{I}_{2}$, on illumination with artifical Na-light. ${ }^{13}$ After $25 \mathrm{~h}$ a $60 \%$ pigment recovery was obtained; $80 \%$ of the reaction mixture was IX.

Absorption spectrum in visible light. Trans IX had abs. max. at $482.5 \mathrm{~m} \mu$ in pet.ether, $483 \mathrm{~m} \mu$ in acetone and $480 \mathrm{~m} \mu$ in methanol.

$R_{F}$-value. Trans IX had $R_{F}=0.64$ on kieselguhr paper in $5 \%$ acetone-pet.ether.

Acknowledgements. The authors are indebted to Dr. O. Isler, Hoffman-La Roche, Basel, for a gift of synthetic $\beta$-apo-4'-carotenoic acid $\left(\mathrm{C}_{35}\right)$ methyl ester and to Norges Almenvitenskapelige Forskningsråd and Norges Tekniske Høgskoles Fond for grants. 


\section{REFERENCES}

1. Karrer, P. and Jucker, E. Carotinoide, Verlag Birkhäuser, Basel 1948.

2. Liaaen Jensen, S. and Jensen, A. Progr. Chem. Fats Lipids 8 (1965) Pt. 2.

3. Isler, O., Guex, W., Rüegg, R., Ryser, G., Saucy, G., Schwieter, U., Walter, M. and Winterstein, A. Helv. Chim. Acta 42 (1959) 864.

4. Haxo, F. Arch. Biochem. 20 (1949) 400.

5. Haxo, F. Fortschr. Chem. Org. Naturstoffe 12 (1955) 169.

6. Zalokar, M. Arch. Biochem. Biophys. 70 (1957) 568.

7. Rau, W. and Zehender, C. Arch. Mikrobiol. 32 (1959) 423.

8. Davies, B. H. Phytochemistry 1 (1961) 25.

9. Zalokar, M. Arch. Biochem. Biophys. 50 (1954) 71.

10. Grob, E. C. Chimia 12 (1958) 86.

11. Liaaen Jensen, S. Phytochemistry 4 (1965) 925.

12. Horowitz, N. H. J. Biol. Chem. 171 (1947) 255.

13. Liaaen Jensen, S. Acta Chem. Scand. 19 (1965) 1166.

14. Karrer, P. and Leumann, E. Helv. Chim. Acta 34 (1951) 445.

15. Shantz, E. M., Caroley, J. D. and Embree, N. D. J. Am. Chem. Soc. 65 (1943) 901.

16. Jensen, A. and Liaaen Jensen, S. Acta Chem. Scand. 13 (1959) 1863.

17. Jensen, A., Aasmundrud, O. and Eimhjellen, K. E. Biochim. Biophys. Acta 88 (1964) 466.

18. Weedon, B. C. L. Private communication.

19. Brockmann, H. and Schodder, H. Ber. 74 (1941) 73.

20. Liawen Jensen, S. Acta Chem. Scand. 17 (1963) 303.

21. Petracek, F. J. and Zechmeister, L. Anal. Chem. 28 (1956) 1484.

22. Liaaen Jensen, S. Kgl. Norske Videnskab. Selskabs. Skrifter 1962 No. 8.

23. Arndt, F. Org. Syn. 15 (1935) 3.

24. Entschel, R. and Karrer, P. Helv. Chim. Acta 41 (1958) 402.

Received June 24, 1965. 